\title{
UN PROTOCOLO DE EMBRIOGÉNESIS SOMÁTICA PARA LA REGENERACIÓN Y CARACTERIZACIÓN IN VITRO DE Laelia anceps ssp. dawsonii
}

\section{A PROTOCOL OF SOMATIC EMBRYOGENESIS FOR THE IN VITRO REGENERATION AND CHARACTERIZATION OF Laelia anceps ssp. dawsonii}

\author{
Hilda E. Lee Espinosa ${ }^{1,2}$, Antonio Laguna Cerda ${ }^{1}$, Joaquín Murguía González ${ }^{2}$, Lourdes Iglesias-Andreu ${ }^{3}$, \\ Benjamín García Rosas ${ }^{2}$, Diana Escobedo López ${ }^{1}$, Yolanda M. Martínez Ocampo ${ }^{2}$, Felipe A. Barredo Pool ${ }^{4}$ \\ y Nancy Santana Buzzy ${ }^{4}$
}

\begin{abstract}
${ }^{1}$ Universidad Autónoma del Estado de México, Programa de Maestría y Doctorado en Ciencias Agropecuarias y Recursos Naturales, Centro Universitario "El Cerrillo" Km. 15 Carretera Toluca-Ixtlahuaca. ${ }^{2}$ Lab. de Cultivo in vitro de Tejidos Vegetales, Facultad de Ciencias Biológicas-Agropecuarias, Universidad Veracruzana. Km. 1, Carretera Peñuela-Amatlán, Peñuela, Mpio. de Amatlán de los Reyes, Veracruz. Tel-Fax: (271)71-66410 y 66129. ${ }^{3}$ Lab. Biotecnología y Ecología Aplicada (INBIOTECA), Universidad Veracruzana. 91001, Xalapa, Veracruz, México. ${ }^{4}$ Unidad de Bioquímica y Biología Molecular de Plantas, Centro de Investigación Científica de Yucatán, Calle 43 Núm. 130, Col. Chuburná de Hidalgo. 97200, Mérida, Yucatán, México.
\end{abstract}

* Autor para correspondencia (kalapana66@hotmail.com, hlee@uv.mx)

\section{RESUMEN}

Laelia anceps subespecie dawsonii, es una de las orquídeas silvestres mexicanas más apreciadas, con potencial ornamental por sus atractivas características que le permiten cumplir estándares internacionales de calidad $y$ la convierten en una especie económicamente importante. Ello ha provocado su colecta excesiva y el consecuente riesgo de extinción. Para asegurar su conservación, es necesario desarrollar protocolos eficientes de propagación para esta especie, que permitan su uso sustentable y reduzcan la colecta. La embriogénesis somática constituye una tecnología eficiente para la multiplicación in vitro de especies vegetales. En este estudio, se evaluaron las condiciones in vitro para desarrollar un protocolo de embriogénesis somática para Laelia anceps ssp. dawsonii. A partir de semillas se indujo callo embriogénico en el medio Murashige y Skoog suplementado con ácido naftalénacético (ANA), 6-bencilaminopurina (BAP), cinetina (Kin) y ácido indol acético (AIA), en combinaciones múltiples. La combinación ANA + BAP+ AIA (2 mg $\mathrm{L}^{-1}$ de cada una) resultó óptima para inducción de callo pues produjo 611 embriones somáticos en fotoperiodo de $16 \mathrm{~h}\left(33.8 \mu \mathrm{mol} \mathrm{m}^{-2} \mathrm{~s}^{-1}\right)$, con tres subcultivos a intervalos de $45 \mathrm{~d}$ en el mismo medio de cultivo, en el que además los embriones desarrollaron plántulas completas. En aproximadamente tres meses, las plántulas alcanzaron 4 a $5 \mathrm{~cm}$ en el medio Vacin y Went suplementado con BAP $\left(2 \mathrm{mg} \mathrm{L}^{-1}\right)$, AIA $\left(1 \mathrm{mg} \mathrm{L}^{-1}\right)$ y carbón activado $(0.2 \%)$, y después de $30 \mathrm{~d}$, se aclimataron en invernadero, con $95 \%$ de sobrevivencia.

Palabras clave: Laelia anceps ssp. dawsonii, cultivo in vitro, embriogénesis somática, Orchidaceae.

\section{SUMMARY}

Laelia anceps ssp. dawsonii is one of the most appreciated Mexican wild orchids, with atractive characteristics for ornamental potential according to international standards. It has become an important economic species, subjected to excessive collection and risk of ex- tinction. To ensure its conservation, it is necessary to develop efficient propagation protocols which allow its sustainable utilization and reduce collection. Somatic embryogenesis is an efficient technology for in vitro plant multiplication. In this study we evaluated in vitro conditions for developing a somatic embryogenesis protocol for Laelia anceps ssp. dawsonii. Embryogenic calli was induced from mature seeds, in a Murashige and Skoog medium supplemented with multiple combinations of naphthalene acetic acid (NAA), 6-benzylaminopurine (BAP), kinetin (Kin) and indole 3 acetic acid (IAA). The combination NAA+BAP+IAA $\left(2.0 \mathrm{mg} \mathrm{L}^{-1}\right.$ each) was optimal for callus induction, producing 611 embryoids in a $16 \mathrm{~h}$ photoperiod $\left(33.8 \mu \mathrm{mol} \mathrm{m}^{-2} \mathrm{~s}^{-1}\right)$ when subcultured every $45 \mathrm{~d}$ on the same medium. This conditions allowed for complete plantlet development. In approximately three months, plantlets achieved 4-5 $\mathrm{cm}$ in a V\&W medium supplemented with BAP $\left(2 \mathrm{mg} \mathrm{L}^{-1}\right)$, AIA (1 $\mathrm{mg} \mathrm{L}^{-1}$ ) and $0.2 \%$ activated charcoal; after $30 \mathrm{~d}$ plantlets were acclimatized in a greenhouse with $95 \%$ survival rate.

Index words: Laelia anceps ssp. dawsonii, in vitro culture, somatic embryogenesis, Orchidaceae.

\section{INTRODUCCIÓN}

Laelia es un género que agrupa aproximadamente 11 especies. Son orquídeas silvestres epífitas originarias de México, y han sido reportadas en las sierras de la vertiente del Golfo de México en los Estados de Hidalgo, Puebla, Veracruz, Tamaulipas, Michoacán, Guanajuato, Querétaro, San Luis Potosí, Morelos, Chiapas y Oaxaca, y probablemente en Guerrero y Jalisco (Bechtel, 1990; Halbinger, 1993). El enlace tropical de Norte, Centro y Sudamérica puede albergar a miembros distintivos de la alianza Cattleya, y entre las miríadas de especies de Epidendrum y Encyclia, las Laelias de México, sobresalen como un vistoso grupo de gran atractivo. Soto 
(1993) propuso la clasificación de Laelia anceps, y reconoció la subespecie dawsonii en la que se sitúan las formas chilapensis y dawsonii. La primera, originaria de Guerrero, posee flores de pétalos rosados y labelo rojo muy oscuro; la segunda forma inflorescencias de 40 a 60 $\mathrm{cm}$ de largo, con una a tres grandes flores blancas $(12 \mathrm{~cm}$ de diámetro), y vistosas en la parte terminal, lóbulo medio del labelo color púrpura oscuro y en el centro un callo amarillo con tres bordes; la garganta presenta rayas bifurcadas en diferentes tonos de amarillo-naranja.

Sus características tan atractivas han provocado un exceso de extracción para venderla como planta para maceta, por lo que se encuentra en peligro de extinción (Halbinger, 1993) y se incluye en la Norma Oficial Mexicana NOM-059-ECOL-2001. Esta situación se agrava porque la especie tiene una baja tasa de propagación, pues al igual que las demás orquídeas sus semillas carentes de endospermo poseen baja capacidad de germinación (1 a $5 \%$ ), relacionada con la obligatoria asociación micorrícica (Martin y Pradeep, 2003). El desarrollo de metodologías que permitan la propagación eficiente de esta especie, representa una alternativa para su conservación y uso sustentable, así como una estrategia para evitar la colecta de ejemplares en la naturaleza.

Desde hace tres décadas el cultivo in vitro de tejidos vegetales ha demostrado su utilidad en la propagación de especies amenazadas, porque ofrece la posibilidad de multiplicar plantas a escalas mayores que las obtenidas a través de los procedimientos tradicionales (Seeni y Latha, 1992; Rao, 1998; Murthy y Pyati, 2001; Lee y Lee, 2003; Shimura y Koda, 2004). La embriogénesis somática de alta frecuencia es una importante aplicación del cultivo de tejidos vegetales, que permite la propagación masiva mediante la regeneración de embriones somáticos (ES) (estructuras bipolares, independientes del tejido original) con alta capacidad reproductiva (George y Sherrington 1984). Se han desarrollado numerosos protocolos de embriogénesis somática en orquídeas, a partir de diferentes tipos de explante: yemas axilares, ápices, secciones de hoja y semillas fecundadas e inmaduras (Chen y Chang, 2000, 2003, 2004b; Huan et al., 2004 b), e incluso se ha logrado la inducción de embriogénesis somática repetitiva en Phalaenopsis amabilis var. formosa shimadzu (Chen y Chang, 2004a).

La regeneración de orquídeas a partir de callo normalmente se desarrolla a través de la formación de estructuras evidentemente embriogénicas denominadas cuerpos parecidos a protocormos (PLB, por sus siglas en ingles). Sin embargo, la embriogénesis somática en cultivos de callos de orquídeas es todavía limitada (Huan et al., 2004). Se ha investigado la germinación in vitro de semillas de diferentes especies del género Laelia que incluyen a $L$. albida (Santos-Hernández et al., 2005), $L$. rubescens Lindley (Potisek et al., 1996), L. autumnalis (Ávila y Salgado, 2006), pero no hay reportes de la inducción de embriogénesis somática en Laelia anceps. El objetivo del presente trabajo fue evaluar el efecto de combinaciones de fitohormonas y medios de cultivo, así como condiciones de incubación y periodos de subcultivo en la formación de embriones somáticos a partir de semillas fecundadas de Laelia anceps ssp. dawsonii, para desarrollar un protocolo eficiente de embriogénesis somática.

\section{MATERIALES Y MÉTODOS}

\section{Material vegetal y medios de cultivo}

Fuente de explantes. Se utilizaron plantas madre de la especie Laelia anceps ssp. dawsonii colectadas en la región de Totutla-Huatusco, y cultivadas en el municipio de Fortín de las Flores, Ver. Las flores se polinizaron manualmente y las cápsulas se cosecharon antes de su dehiscencia; las semillas se sembraron in vitro.

Composición del medio de cultivo. Los medios de cultivo utilizados estuvieron compuestos por las sales minerales de Murashige y Skoog (1962) (MS), Knudson C (1946) (KC) y Vacin y Went (1949) (VW). En todos los casos, los medios se suplementaron con mio-inositol (100 mg L $\left.\mathrm{L}^{-1}\right)$, sacarosa $\left(30 \mathrm{~g} \mathrm{~L}^{-1}\right)$, y se solidificaron con Phytagel ${ }^{\circledR}\left(2.5 \mathrm{~g} \mathrm{~L}^{-1}\right)$. En los medios MS y KC el pH fue ajustado a 5.7 y en el medio $\mathrm{VW}$ a 4.8 , previo a la esterilización en autoclave durante $15 \min$ a $121^{\circ} \mathrm{C}$.

\section{Inducción de callo embriogénico}

Para la inducción de callo se utilizaron los medios de cultivo MS y VW, suplementados con dos combinaciones de reguladores del crecimiento: ácido naftalénacético (ANA) +6-bencilami-nopurina (BAP) + ácido indol acético (AIA) y ANA+BAP (2.0 mg L $\mathrm{m}^{-1}$ de cada uno). Estos medios se esterilizaron y dosificaron a razón de 15 $\mathrm{mL}$ en cajas de Petri esterilizadas, donde se sembraron 5 mg de semillas maduras. En total se utilizaron 20 cajas de Petri para cada tratamiento. Los cultivos se incubaron en fotoperiodo de $16 \mathrm{~h}\left(20.2 \mu \mathrm{mol} \mathrm{m} \mathrm{m}^{-2} \mathrm{~s}^{-1}\right.$, provista por lámparas de luz fluorescente tipo blanco-frío) y $8 \mathrm{~h}$ de oscuridad, a $23 \pm 1{ }^{\circ} \mathrm{C}$. A los $45 \mathrm{~d}$ se evaluó la formación de callos con capacidad morfogénica. 


\section{Condiciones de incubación y medios de cultivo para} inducir la morfogénesis de los callos desarrollados

Con el fin de determinar el efecto de las condiciones de cultivo en la morfogénesis de los callos, se estableció un experimento con diseño completamente al azar, en el que se evaluaron tres medios de cultivo basales (MS, KC y VW) suplementados con $2.0 \mathrm{mg} \mathrm{L}^{-1}$ de ANA, BAP, AIA, y dos condiciones de incubación: fotoperiodo 16 h $(33.8$ $\mu$ mol m $\mathrm{m}^{-2} \mathrm{~s}^{-1}$ y oscuridad. Se sembraron diez callos de $\approx 2$ $\mathrm{mm}$ de diámetro por tratamiento, seleccionados por su textura rugosa, consistencia friable y color verde intenso. A las cinco semanas se evaluó el número de embriones somáticos formados.

\section{Tipos y combinaciones de fitohormonas en la morfogénesis}

Porciones de callo ( $\approx 2 \mathrm{~mm}$ de diámetro) se cultivaron en el medio MS suplementado con $100 \mathrm{mg} \mathrm{L}^{-1}$ de mioinositol, $30 \mathrm{~g} \mathrm{~L}^{-1}$ de sacarosa, $2 \mathrm{~g} \mathrm{~L}^{-1}$ de Phytagel ${ }^{\circledR}$ y tres combinaciones de fitohormonas: ANA + BAP+AIA, $\mathrm{Kin}+\mathrm{ANA}+\mathrm{BAP}$ y ANA + BAP, cada una a $2 \mathrm{mg} \mathrm{L}^{-1}$. Se utilizaron cuatro repeticiones por tratamiento y cada unidad experimental estuvo constituida por un frasco de vidrio de $5.7 \times 7.0 \mathrm{~cm}$ que contenía $20 \mathrm{~mL}$ del medio de cultivo y diez porciones de callo. El tratamiento testigo no contenía fitohormonas. Los cultivos se incubaron en fotoperiodo de $16 \mathrm{~h}\left(33.8 \mu \mathrm{mol} \mathrm{m}^{-2} \mathrm{~s}^{-1}\right)$ y $8 \mathrm{~h}$ de oscuridad a $23 \pm 1{ }^{\circ} \mathrm{C}$. Se contó el número de embriones formados en cada tratamiento, a las cuatro y seis semanas de cultivo.

\section{Capacidad de proliferación de los embriones somáticos}

Tiempo de cultivo e índice de multiplicación (IM) de los embriones somáticos. Con el propósito de determinar el efecto de las sales minerales y el tiempo de cultivo en la capacidad de proliferación de embriones somáticos de Laelia anceps ssp. dawsonii, y calcular su índice de multiplicación (IM) cuando no se efectúan subcultivos a medio de cultivo fresco, se estableció un experimento completamente al azar en el que se probaron tres medios de cultivo: MS, KC y VW, adicionados con ANA + BAP + AIA $\left(2 \mathrm{mg} \mathrm{L}^{-1} \mathrm{c} / \mathrm{u}\right)$, y suplementados con $100 \mathrm{mg} \mathrm{L}^{-1}$ de mio-inositol, $5 \mathrm{~mL} \mathrm{~L}^{-1}$ de vitaminas MS, $30 \mathrm{~g} \mathrm{~L}^{-1}$ de sacarosa y $2 \mathrm{~g} \mathrm{~L}^{-1}$ de Phytagel ${ }^{\circledR}$. Se utilizaron diez repeticiones por tratamiento y cada unidad experimental estuvo constituida por un frasco de vidrio de $5.7 \times 7.0 \mathrm{~cm}$ que contenía $20 \mathrm{~mL}$ del medio de cultivo, con cinco embriones somáticos. Los cultivos se incubaron durante diez semanas en fotoperiodo de $16 \mathrm{~h}(33.8 \mu \mathrm{mol}$ $\mathrm{m}^{-2} \mathrm{~s}^{-1}$ ) y $8 \mathrm{~h}$ de oscuridad, a $23 \pm 1{ }^{\circ} \mathrm{C}$. El recuento del número de embriones somáticos (ES) desarrollados se hizo cada dos semanas, en dos frascos al azar en cada evaluación, para calcular el número de veces que cada embrión somático se multiplicó en el periodo evaluado o índice de multiplicación, como sigue:

Índice de multiplicación (IM) $=\Sigma(\mathrm{ES}$ formados por trat. ES inicial).

Tiempo de subcultivo y capacidad de multiplicación de embriones somáticos. Para determinar el efecto de las sales minerales y el tiempo de subcultivo en la capacidad de proliferación de Laelia anceps ssp. dawsonii, se estableció un experimento completamente al azar en el que se cultivaron embriones somáticos en etapas tempranas de su desarrollo, con 12 repeticiones por tratamiento, y cada unidad experimental estuvo constituida por un frasco de vidrio de $5.7 \times 7.0 \mathrm{~cm}$ que contenía $20 \mathrm{~mL}$ del medio de cultivo con cinco embriones somáticos. Se evaluaron los medios MS, KC y VW, suplementados con $100 \mathrm{mg} \mathrm{L}^{-1}$ de mio-inositol, $30 \mathrm{~g} \mathrm{~L}^{-1}$ de sacarosa, $2 \mathrm{~g} \mathrm{~L}^{-1}$ de Phytagel ${ }^{\circledR}$, y $2.0 \mathrm{mg} \mathrm{L}^{-1} \mathrm{de}$ ANA + BAP+AIA; los tiempos de subcultivo evaluados fueron de $21,30,45$ y $90 \mathrm{~d}$, en condiciones de fotoperiodo de $16 \mathrm{~h}\left(33.8 \mu \mathrm{mol} \mathrm{m}^{-2} \mathrm{~s}^{-1}\right)$ y $8 \mathrm{~h}$ de oscuridad, a $23 \pm 1{ }^{\circ} \mathrm{C}$. En cada periodo se efectuaron tres subcultivos, excepto en el de 90 d que se subcultivó sólo una vez. La evaluación de los embriones somáticos formados se hizo a los $180 \mathrm{~d}$ de cultivo. El testigo no fue subcultivado.

\section{Análisis histológico de la morfogénesis de Laelia anceps ssp. dawsonii}

Para determinar la vía morfogénica de regeneración y el origen de las estructuras formadas in vitro, se efectuaron análisis histológicos de los callos regenerados. Para ello, las muestras se fijaron por $24 \mathrm{~h}$ en FAA (formaldehido: ácido acético glacial: etanol $96 \%$ : agua destilada $=10: 5: 50: 35, \mathrm{v} / \mathrm{v} / \mathrm{v} / \mathrm{v})$. Posteriormente fueron transferídas a etanol $70 \%$ por $12 \mathrm{~h}$, y deshidratadas en series de etanol $(30,50,70,85$ y $96 \%)$. En el último paso de deshidratación se hicieron tres cambios sucesivos, de 45 min cada uno, en etanol absoluto (100\%). Los tejidos deshidratados se infiltraron en la resina plástica del kit JB4 de metacrilato de glicol (PolySciences; Los Angeles, CA, USA), primero se colocaron las muestras por $24 \mathrm{~h}$ en alcohol etílico anhidro:resina de infiltración $=1: 1 \mathrm{v} / \mathrm{v}, \mathrm{y}$ $1: 2 \mathrm{v} / \mathrm{v}$ después. Finalmente las muestras se mantuvieron en la solución de infiltración pura (sin alcohol) durante 48 a 72 h. Para la inclusión se mezcló la solución de infiltración con N-N dimetil-anilina, y se vertió en moldes de polipropileno (13 x $19 \mathrm{~mm})$ que contenían las muestras. Se hicieron cortes de 3 a $7 \mu \mathrm{m}$ de espesor con un microtomo de rotación Microm HM 325® 
(Polysciences, Inc.; Warrington, USA), se fijaron en serie sobre portaobjetos (Sigma Techware; $25 \times 75$ x $1 \mathrm{~mm}$ ) por calentamiento en placa Thermolyne ${ }^{\mathrm{TM}}$, Nuova II, calibrada entre 38 y $40{ }^{\circ} \mathrm{C}$ (Piven et al., 2001) y se tiñeron con azul de toluidina. Las observaciones de los callos y los diferentes estadios de las estructuras embriogénicas desarrolladas, se hicieron con microscopio óptico Axioplane Carl Zeiss ${ }^{\circledR}$ (Carl Zeiss MicroImaging, LLC; Thornwood, NY., USA), de óptica en campo claro.

\section{Germinación y conversión de los embriones somáticos}

Los embriones somáticos en las etapas de torpedo y de plúmula se cultivaron en el medio $\mathrm{VW}$, suplementado con mio-inositol $\left(100 \mathrm{mg} \mathrm{L}^{-1}\right)$, sacarosa $\left(30 \mathrm{~g} \mathrm{~L}^{-1}\right)$, vitaminas MS $\left(5 \mathrm{~mL} \mathrm{~L}^{-1}\right)$, BAP $\left(2 \mathrm{mg} \mathrm{L}^{-1}\right)$, AIA $\left(1 \mathrm{mg} \mathrm{L}^{-1}\right)$ y carbón activado $\left(2 \mathrm{~g} \mathrm{~L} \mathrm{~L}^{-1}\right)$, y una vez desarrolladas fueron transferidas a invernadero para su aclimatización, y sembradas en un sustrato compuesto por una mezcla de "peat moss" y piedra volcánica $1: 1 \quad(\mathrm{v} / \mathrm{v})$ donde permanecieron durante $30 \mathrm{~d}$, para evaluar la supervivencia de las plantas; el final del periodo se determinó con la aparición de una nueva hoja.

\section{Análisis estadístico de los datos}

Todos los datos fueron procesados mediante un análisis de varianza, con el paquete estadístico SAS System, Versión 6.12 (SAS Institute, 1989-1997) y discriminados con la prueba de comparación de medias de Tukey $\alpha \leq$ 0.05 (Steel y Torrie, 1980).

\section{RESULTADOS}

\section{Inducción de callo embriogénico}

Durante la inducción de callo se observó que en el medio MS que contenía $2 \mathrm{mg} \mathrm{L}^{-1}$ de ANA + BAP+AIA, el callo formado fue abundante, de consistencia friable y color verde tenue cristalino, con puntos verde intenso dispersos en toda la masa morfogénica (Figura $1 \mathrm{~A}, \mathrm{~B}$ ), lo que permite inferir su naturaleza embriogénica. En contraste, cuando se utilizó la misma combinación de reguladores del crecimiento en el medio VW, únicamente se logró germinación de todas las semillas, apreciada por la formación de protocormos (PLBs) ligeramente ensanchados en la zona basal y más afinados hacia el extremo apical (Figura $1 \mathrm{C}$, D), pero sin inducción de morfogénesis, que pudiera resultar en la formación de callo. En el medio MS con ANA y BAP $\left(2 \mathrm{mg} \mathrm{L}^{-1} \mathrm{de} \mathrm{c} / \mathrm{u}\right)$ hubo escasa formación de callo que degeneró rápidamente para tornarse café-amarillento, con la formación de protocormos aislados. Cuando la misma combinación de reguladores del crecimiento se adicionó al medio VW, únicamente hubo germinación de semillas.

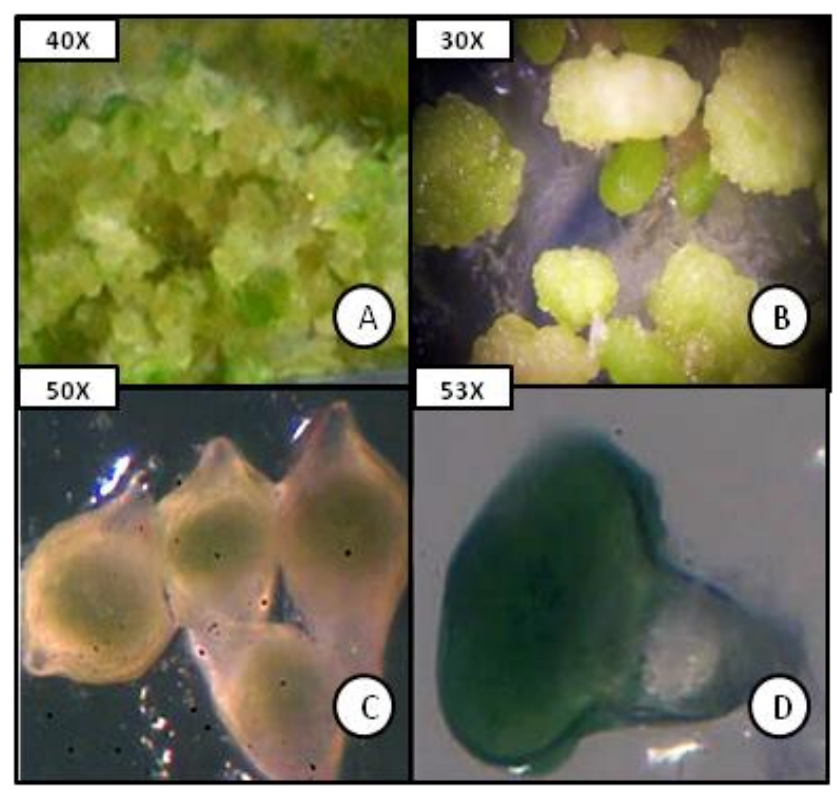

Figura 1. Inducción de morfogénesis en semillas germinadas de $L$. anceps ssp. dawsonii: A y B: Formación de callo en el medio MS suplementado con ANA, BAP y AIA ( $2 \mathrm{mg} \mathrm{L}^{-1}$ cada uno); C y D: Germinación de semillas en el medio VW adicionado con ANA, BAP, AIA ( $2 \mathrm{mg} \mathrm{L}^{-1}$ de cada uno) a los $45 \mathrm{~d}$ de su desarrollo in vitro.

\section{Condiciones de incubación y medios de cultivo} en la morfogénesis de los callos desarrollados

Como resultado de la exposición de los callos a fotoperiodo y oscuridad, se observó mayor eficiencia en la proliferación de callo y formación de embriones somáticos en el fotoperiodo de $16 \mathrm{~h}\left(33.8 \mu \mathrm{mol} \mathrm{m}^{-2} \mathrm{~s}^{-1}\right)$, con el medio MS que estimuló la formación de 165.2 ES en promedio, y callo embriogénico de color verde intenso, mientras que con el medio KC se formaron 97.6 ES. En oscuridad el medio MS logró inducir en promedio 86 embriones y en KC sólo 56.6. El medio VW presentó menor capacidad morfogénica en las dos condiciones evaluadas, con apenas 26 ES en 16 h-luz y 15.2 en oscuridad (Figura 2). La respuesta morfogénica siguió un patrón de desarrollo similar al de diferenciación por embriogénesis somática, descrito para otras especies de orquídeas, como Oncidium (Chen y Chang, 2000) y Cymbidium (Huan et al., 2004).

En la Figura 3 se muestra que la formación de ES en los tres medios de cultivo fue marcadamente superior cuando el proceso ocurrió en fotoperiodo de $16 \mathrm{~h}$ y fue más eficiente cuando los cultivos se desarrollaron en los medios MS y $\mathrm{KC}$; en el medio VW el callo generado siempre mostró tonalidad de verde blanquecino a café debido a la oxidación del tejido, lo que ocasionó 
producción casi nula de embriones somáticos, aún cuando los callos desarrollados en oscuridad posteriormente se pasaron a condiciones de fotoperiodo. Estas observaciones demuestran que las condiciones de incubación influyen en la inducción de embriogénesis somática de los callos y la posterior regeneración de embriones. Respecto a la combinación de las sales MS con el balance auxina- citocinina, se observó que los ES desarrollados en fotoperiodo tomaron coloración verde intensa con marcada tendencia a formar callo embriogénico de consistencia friable que al contacto sus estructuras independientes se separaban, y con ápices radical y caulinar perfectamente definidos que demuestra la ocurrencia de embriogénesis somática típica.

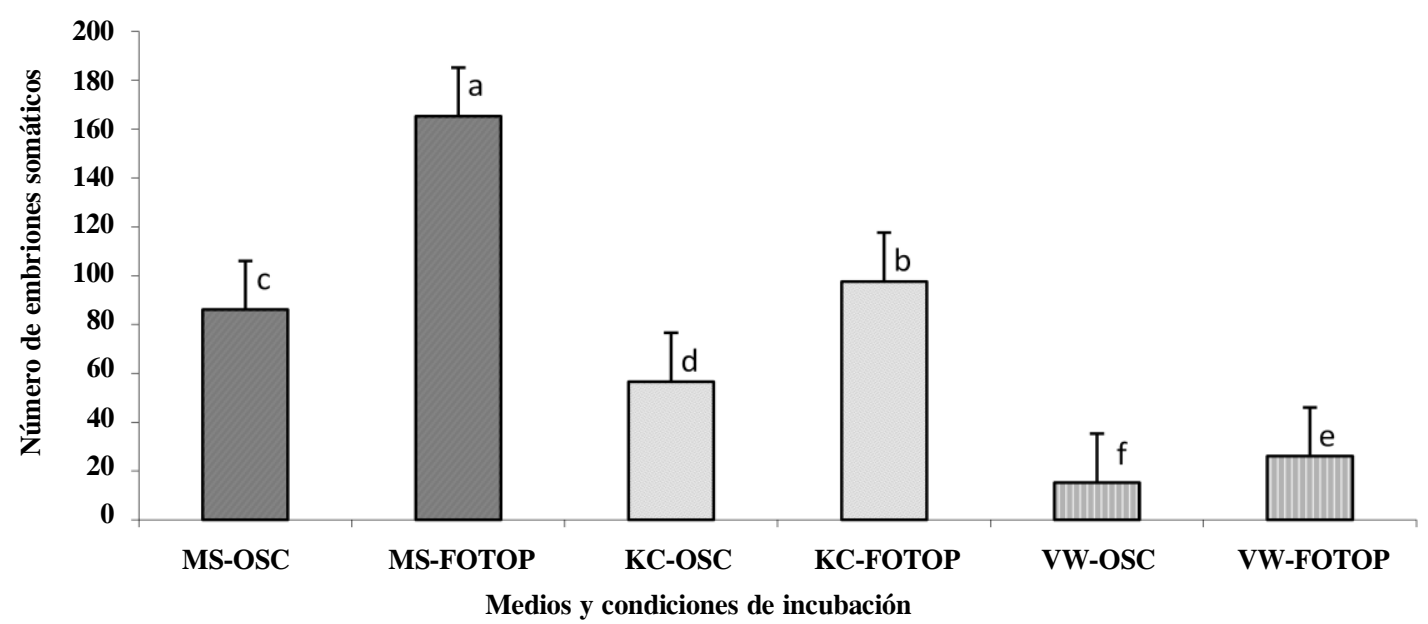

Figura 2. Efecto del medio de cultivo (MS, KC, VW) y condiciones de incubación (oscuridad y fotoperiodo de 16 h, 33.8 $\mu \mathrm{mol} \mathrm{m} \mathrm{m}^{-2} \mathrm{~s}^{-1}$ ) en la proliferación de embriones somáticos de Laelia anceps ssp. dawsonii. Medias con letras iguales no son estadísticamente diferentes (Tukey, 0.05); CV $=1.3 \%$.
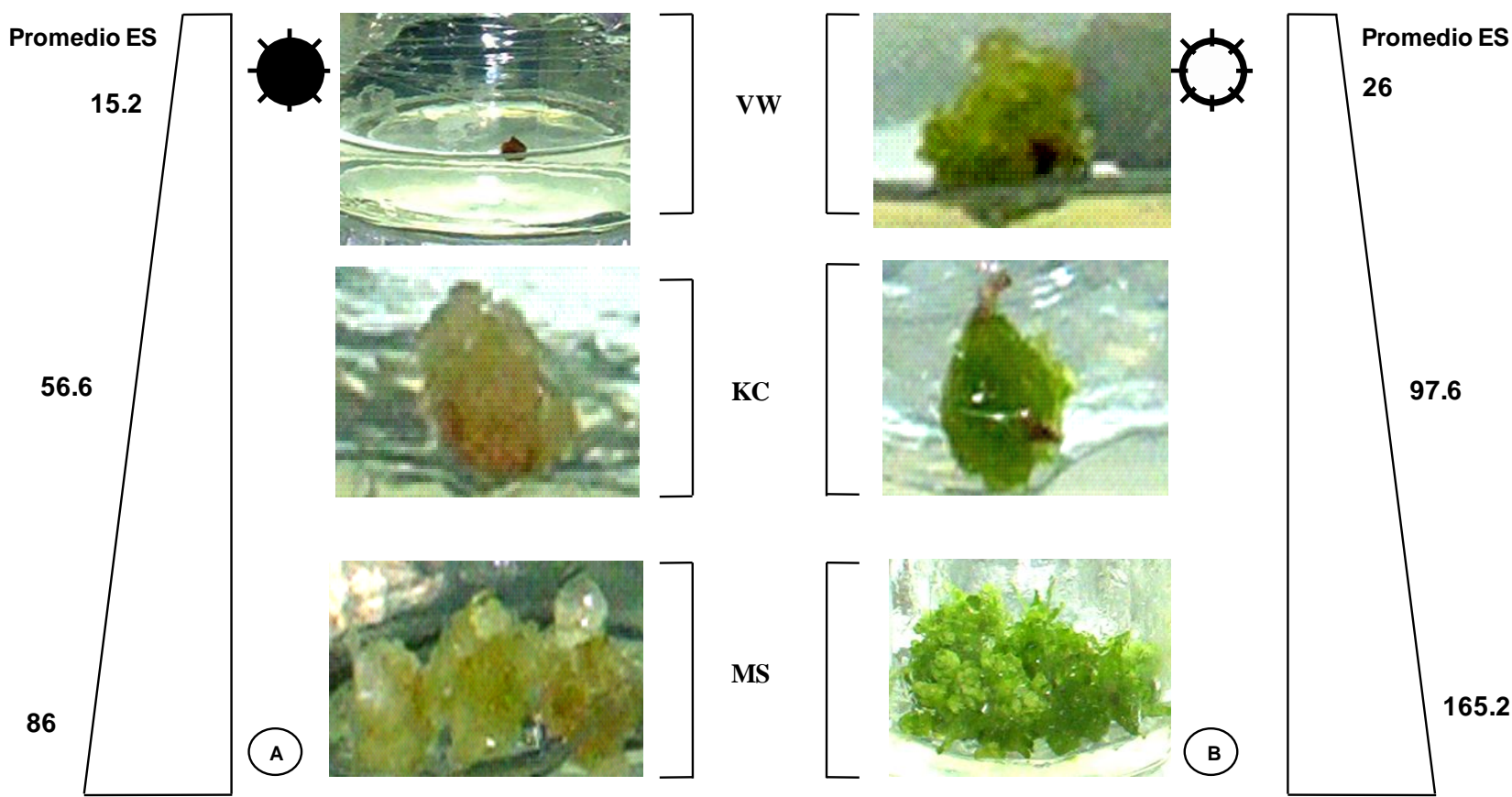

Figura 3. Morfogénesis de callos embriogénicos de L. anceps ssp. dawsonii desarrollados en tres medios de cultivo (MS, KC y VW), y dos condiciones de incubación: A) Oscuridad y B) Fotoperiodo; ES = Embriones somáticos. 


\section{Tipos y combinaciones de fitohormonas en la morfogénesis}

Los segmentos de callo difirieron en capacidad morfogénica entre las combinaciones de fitohormonas utilizadas, lo que constata la capacidad de proliferación de los ES, y que alcanzó su máxima eficiencia a las seis semanas de establecido el experimento, en los tres tratamientos, aunque con diferencias significativas entre ellos (Figura 4). Las combinaciones ANA+AIA + BAP produjeron en promedio $425 \mathrm{ES}$, la mayor capacidad de multiplicación de los callos embriogénicos obtenida en este experimento, en contraste con la combinación Kin+ANA+BAP que mostró la menor capacidad con 202 ES en el mismo tiempo; la combinación ANA+BAP presentó $275 \mathrm{ES}$; a las cuatro semanas de cultivo se observó menor producción de embriones somáticos, con promedios de 311,172 y $245 \mathrm{ES}$, en las combinaciones de fitohormonas ANA+BAP+AIA, Kin+ANA+BAP y ANA + BAP, respectivamente.

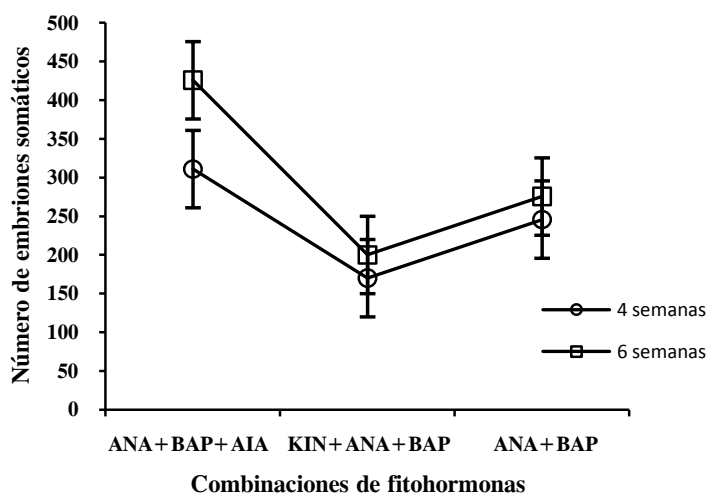

Figura 4. Número de embriones somáticos de Laelia anceps ssp. dawsonii desarrollados en medio MS con ANA,BAP,AIA; KIN,ANA,BAP y ANA,BAP, a las cuatro y seis semanas in vitro. Cada punto representa el promedio de cuatro repeticiones \pm error estándar; DMS = 1.97.

\section{Capacidad de proliferación de los embriones somáticos}

Tiempo de cultivo en el índice de multiplicación (IM) de los embriones somáticos. Los callos continuaron proliferando después de ser transferidos a los medios de cultivo MS, KC y VW, suplementados con ANA + BAP+AIA (2 mg $\mathrm{L}^{-1}$ de c/u), y mantenidos durante 10 semanas en cultivo. El mayor IM de embriones somáticos (92) se alcanzó a las 8 semanas de cultivo cuando se utilizaron las sales MS. En los medios KC y VW los máximos (52 y 12 ES) se obtuvieron a las 8 y 6 semanas de cultivo, respectiva-mente (Figura 5). En todos los casos se observó descenso del IM, una vez alcanzado el nivel óptimo, ya que los embriones somáticos inician el proceso de diferenciación a plántula por carecer de subcultivo a medio fresco que activa la germinación. El medio MS resultó mejor que los medios $\mathrm{KC}$ y VW para inducir proliferación de ES, aunque el tiempo en que se logró este efecto fue el más prolongado. Aunque el medio KC indujo menor proliferación de embriones, podría considerarse suficiente para el inicio del proceso de embriogénesis somática, ya que se trata de un medio menos complejo.

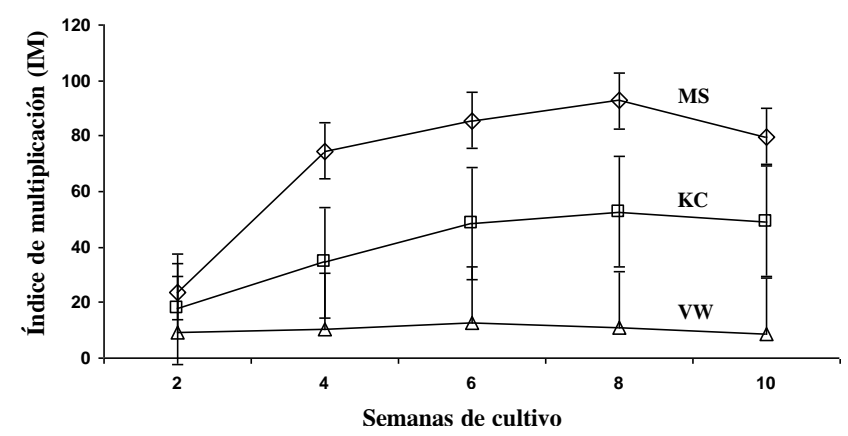

Figura 5. Índice de multiplicación (IM) de embriones somáticos de L. anceps ssp. dawsonii en los medios MS (Murashige y Skoog), KC (Knudson C) y VW (Vacin y Went), suplementados con ANA, BAP, AIA (2 mg L $\mathrm{m}^{-1}$ de cada uno), durante 10 semanas in vitro. Cada punto representa el promedio de diez repeticiones \pm error estándar.

El tiempo de subcultivo y la capacidad de multiplicación de embriones somáticos. $\mathrm{La}$ multiplicación de embriones somáticos se elevó considerablemente en el tercer subcultivo, S3 (Figura 6). Esta tendencia se observó en los tres periodos $(21,30$ y 45 d) y alcanzó su nivel máximo con subcultivos (S3) cada $45 \mathrm{~d}$. Una vez lograda la máxima multiplicación, en todos los casos hubo descenso significativo a los $90 \mathrm{~d}$. El análisis de varianza mostró diferencias $(\mathrm{P} \leq 0.5)$ en el tiempo de subcultivo y número de subcultivos realizados; a intervalos de 45 d se logró la regeneración de 524 ES producidos en los tres subcultivos (Figura 7). Asimismo, fue posible detectar diferencias $(\mathrm{P} \leq 0.5)$ en el número de subcultivos, con 611 ES como el mayor promedio de multiplicación obtenido en el tercer subcultivo, al cabo de $135 \mathrm{~d}$ in vitro.

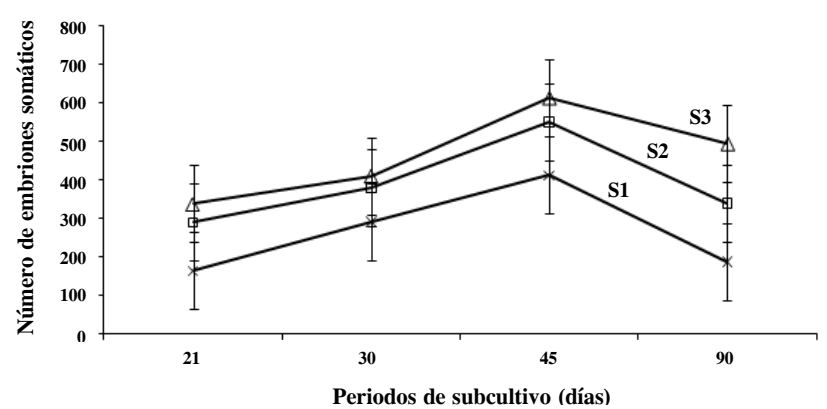

Figura 6. Multiplicación de embriones somáticos de $L$. anceps ssp. dawsonii durante tres subcultivos (S1, S2, S3) a intervalos de 21, 30, 45 y 90 d. Cada punto representa el promedio de tres repeticiones \pm error estándar. 


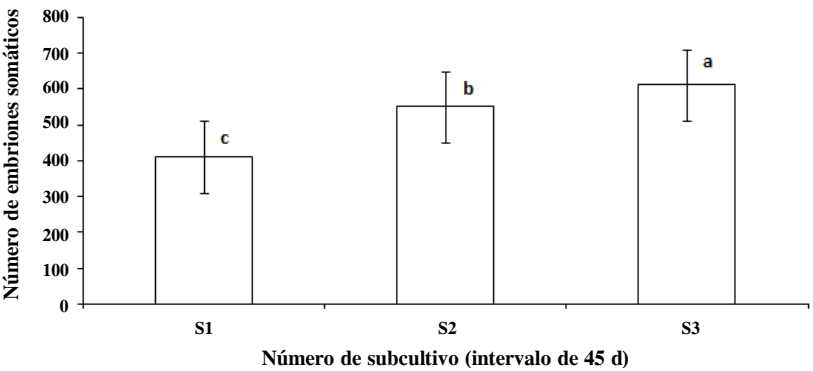

Figura 7. Multiplicación de embriones somáticos de $L$. anceps ssp. dawsonii a intervalos de $\mathbf{4 5} \mathrm{d}$, durante tres subcultivos sucesivos (135 días). Medias con letras iguales no son estadísticamente diferentes (Tukey, 0.05); DMS $=$ 5.0103; CV $=0.04 \%$.

\section{Análisis histológico de la morfogénesis de Laelia anceps ssp. dawsonii}

Las secciones transversal y longitudinal de los callos cultivados en medio MS suplementado con ANA + BAP+AIA $\left(2 \mathrm{mg} \mathrm{L}^{-1} \mathrm{c} / \mathrm{u}\right)$, mostraron estructuras embriogénicas en los estadios globular, torpedo y plúmula. Estas estructuras fueron de morfología similar a los embriones cigóticos desarrollados (PLBs) durante la germinación de semillas de orquídeas (Shimura y Koda, 2004). Mediante el análisis histológico fue posible demostrar que los ES se originaron de callos (Figura $8 \mathrm{~A}$ ) constituidos por células con citoplasmas densos y masas de núcleos prominentes, característicos del tejido embriogénico, concentradas en el sitio donde emergen las estructuras embriogénicas típicas (Figura 8 B). Las estructuras regeneradas del callo (Figura 8 C), eventualmente se transformaron en ES independientes, sin conexión vascular entre ellas y el tejido del que provienen (Figura $8 \mathrm{D}$ ). Las observaciones histológicas demuestran que la regeneración de las plantas ocurrió a través de la formación de embriones somáticos, y que el callo inducido fue embriogénico.

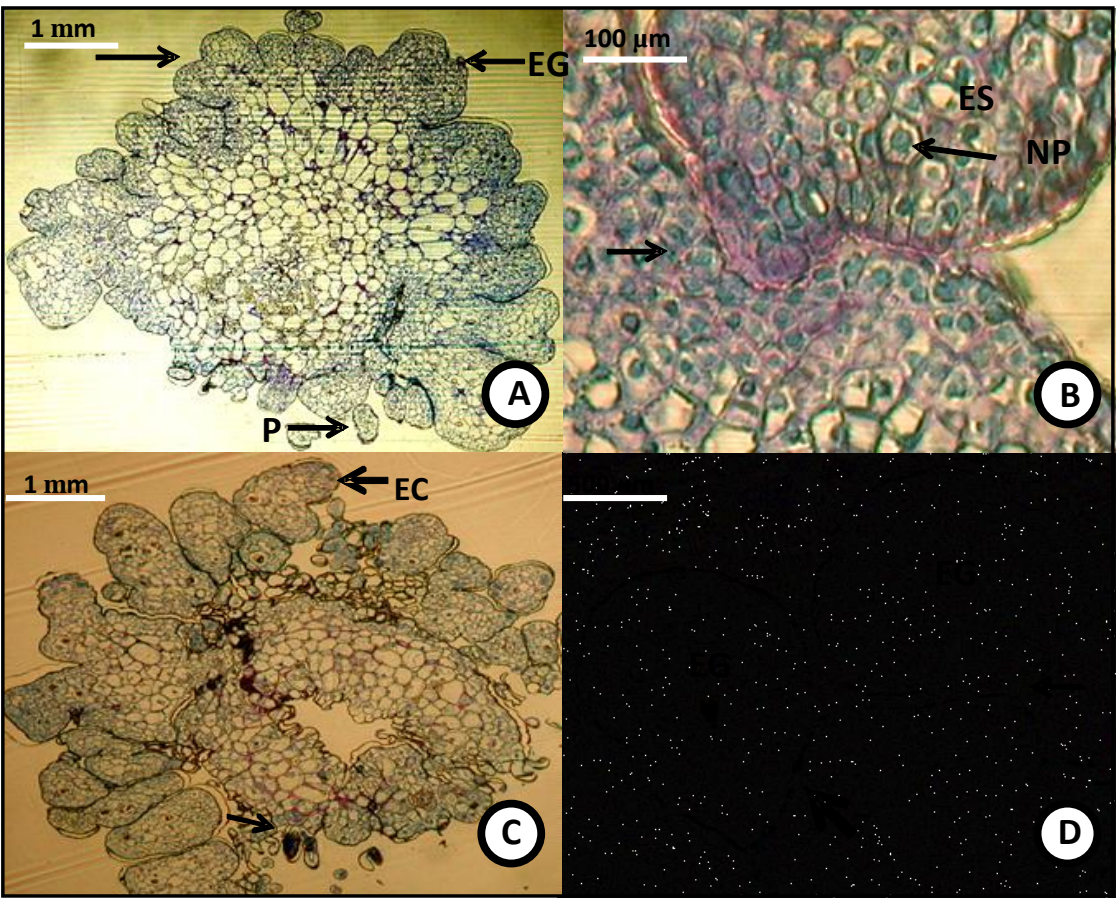

Figura 8. Cortes anatómicos de callos embriogénicos de L. anceps ssp. dawsonii $(3 \mu \mathrm{m}$ espesor de corte) A) Sección transversal de callos que muestra el inicio de la regeneración de estructuras embriogénicas globulares (EG) y plúmulas (P) en su periferia (barra $=1 \mathrm{~mm}$ ); B) Estructuras embriogénicas somáticas típicas (ES) que muestran células con citoplasmas densos y núcleos prominentes (NP) concentradas en el sito de emergencia (barra $=100 \mu \mathrm{m}$ ); C) Estructuras embriogénicas completas (EC) e independientes del callo (barra $=1 \mathrm{~mm}$ ); D) Embriones somáticos en estadio globular (EG), separados del callo, que indican ausencia de conexiones vasculares con el tejido original (barra $=\mathbf{5 0 0} \mu \mathbf{m}$ ). 


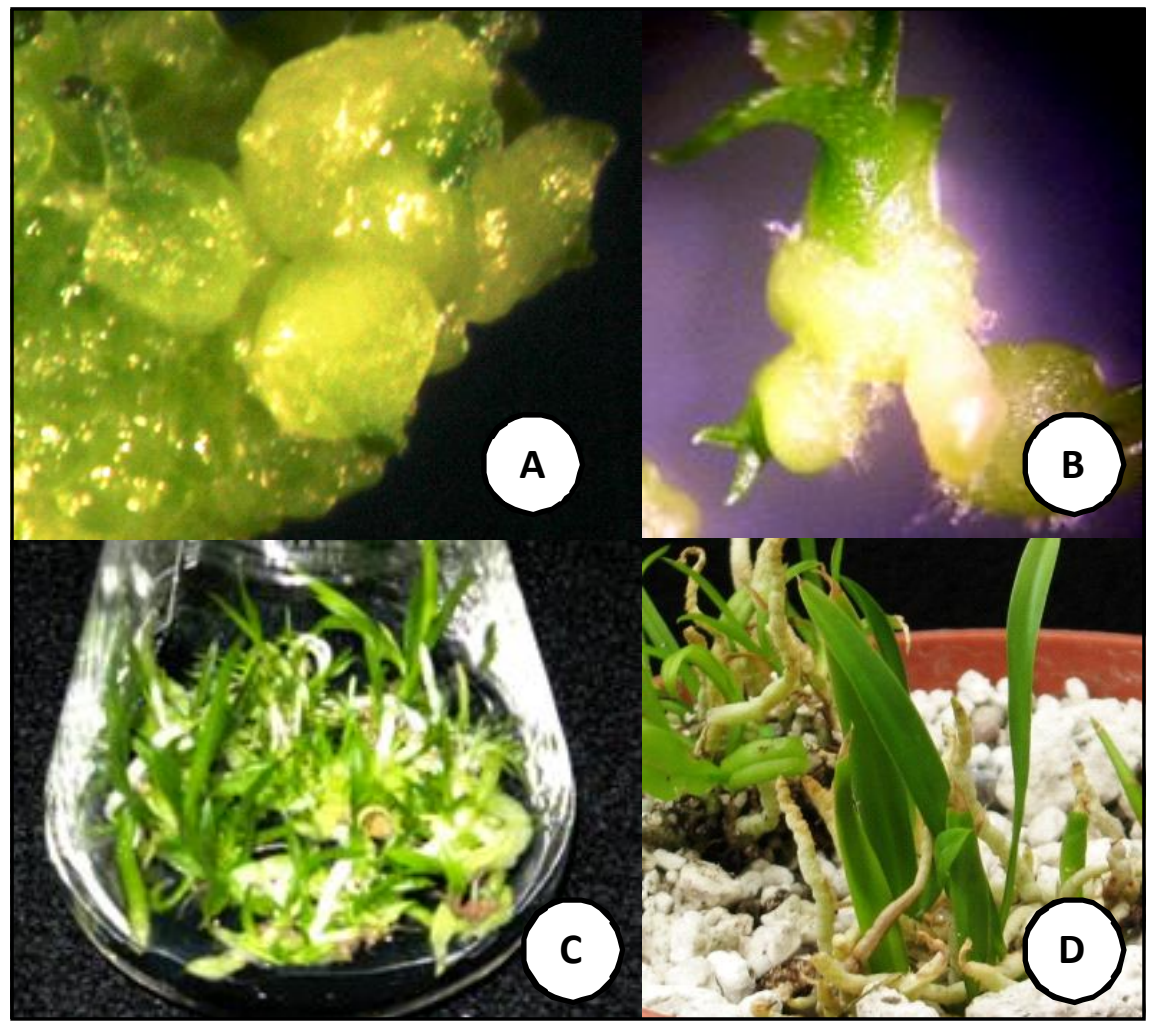

Figura 9. Regeneración de plantas de Laelia anceps ssp. dawsonii a partir de cultivo de callos embriogénicos A) Embriones generados a partir de callos verdes; B) Plantas obtenidas de embriones somáticos; C) Plantas completas regeneradas in vitro; D) Plantas que crecen en macetas con sustrato de "peat-moss" y piedra volcánica (1:1 v/v), en invernadero.

\section{Germinación y conversión de los embriones somáticos}

Los ES formados del callo (Figura 9 A) continuaron su multiplicación, y eventualmente desarrollaron brotes y raíces en el medio MS suplementado con ANA + BAP+AIA ( $2 \mathrm{mg} \mathrm{L}^{-1}$ de c/u) (Figura 9 B). Para inducir su desarrollo a plántulas individuales completas, se transfirieron al medio VW suplementado con $\left(\mathrm{mg} \mathrm{L}^{-1}\right)$ : BAP (2.0) + AIA (1.0) hasta su total desarrollo, donde alcanzaron $4-5 \mathrm{~cm}$ de altura (Figura $9 \mathrm{C}$ ); posteriormente fueron trasplantadas a macetas que contenían una mezcla de "peat moss" y piedra volcánica $(1: 1 \mathrm{v} / \mathrm{v})$ como sustrato, en condiciones de invernadero, donde en $30 \mathrm{~d}$, mostraron $95 \%$ de sobrevivencia (Figura 9 D).

\section{DISCUSIÓN}

En el presente estudio se encontró que las condiciones de incubación y medio de cultivo influyeron en el desarrollo de los callos embriogénicos. En oscuridad los callos fueron pequeños $(<5 \mathrm{~mm}$ de diámetro $)$, particularmente los que se formaron en el medio $\mathrm{VW}, \mathrm{y}$ de color verde blanquecino; en el medio $\mathrm{KC}$ se indujo callo más desarrollado ( 5 a $8 \mathrm{~mm}$ de diámetro) y de color verde tenue, al igual que los ES formados en el medio MS mostraron el mismo color que en el medio $\mathrm{KC}$ pero con mejor desarrollo del callo, cuyo diámetro promedio fue mayor a $8 \mathrm{~mm}$. La incubación en fotoperiodo de $16 \mathrm{~h}$ $\left(33.8 \mu \mathrm{mol} \mathrm{m}^{-2} \mathrm{~s}^{-1}\right)$ resultó mejor para la inducción de callo, en todos los medios de cultivo probados, lo cual coincide con los reportes de Chen y Chang (2004a) quienes lograron la inducción de callo en embriones cigóticos de Cymbidium con fotoperiodo de $16 \mathrm{~h}$ a una mayor intensidad lumínica de $45 \mu \mathrm{mol} \mathrm{m} \mathrm{m}^{-2} \mathrm{~s}^{-1}$; los callos de coloración verde intenso generaron ES en mayor número y de aspecto vigoroso, los cuales normalmente desarrollaron sus primeras hojas y raíces sin necesidad de subcultivarlos en medio de cultivo nuevo.

Hubo interacción entre los medios de cultivo y las combinaciones de fitohormonas utilizadas, en la morfogénesis de $L$. anceps ssp. dawsonii, lo que coincide con las observaciones de Fehér et al. (2003), quienes con base en la prueba de una amplia gama de inductores concluyeron que la embriogénesis somática no puede definirse como respuesta específica a uno o más reguladores del crecimiento, porque existen interacciones 
con los componentes del medio. Sin embargo, las fitohormonas son los candidatos más viables en la regulación de señales del desarrollo, como indicaron Huan et al. (2004), en la formación de callo embriogénico en Cymbidium, donde las auxinas y citocininas fueron las principales hormonas involucradas en la regulación de la división y diferenciación celular.

De acuerdo con Dudits et al. (1991), la auxina 2,4-D (ácido 2,4-diclorofenoxiacético) es la más utilizada para la inducción de embriogénesis somática, así como en presencia de citocininas (Sagare et al., 2000) y de AIA; en concentraciones relativamente altas $\left(1 \mathrm{a} 2 \mathrm{mg} \mathrm{L}^{-1}\right)$ el AIA ha mostrado estar asociado con mayor respuesta embriogénica de varias especies vegetales (Rajasekaran et $a l .$, 1987). En Oncidium (Orchidaceae) Chen y Chang (2000) reportaron el uso de auxinas solas y en combinación con citocininas, en dosis desde 3 hasta 10 $\mathrm{mg} \mathrm{\textrm {L } ^ { - 1 }}$ de 2,4-D; así como el uso de 2,4-D en combinación con TDZ (1-fenyl-3-(1,2,3-tidiazol-5-il)urea) para inducir callo embriogénico, y posteriormente ANA (ácido naftalénacético) en combinación con TDZ, en explantes de hoja y ápices de raíz, para promover la formación de embriones somáticos a partir del callo.

En contraste, en el trabajo aquí reportado con $L$. anceps ssp. dawsonii fue posible inducir callo embriogénico y la posterior regeneración y proliferación de embriones somáticos, únicamente con ANA y AIA en combinación con BAP y Kin. En general, el uso de la combinación BAP con ANA y AIA, indujo la mejor respuesta morfogénica y la multiplicación eficiente de embriones somáticos, así como el desarrollo de ES a plántulas. Cuando se utilizó ANA en combinación con una de las citocininas BAP o Kin, disminuyó tanto la inducción de callo como el índice de multiplicación, lo que demuestra que la adecuada combinación de fitohormonas promueve mas la inducción de callo embriogénico, la proliferación de ES y el desarrollo de plántulas, en esta orquídea.

En este estudio, los resultados obtenidos en desarrollo de plántulas y formación de raíces en el medio de inducción coinciden con los de Martin (2003), quien trabajó en la propagación clonal de Ipsea malabárica (Reichb .f.) J. D. Hook, una orquídea endémica de la India y Sri Lanka, y reportó que la inducción de raíces fuertes y carnosas ocurría cuando las plántulas permanecían en el medio de proliferación. En el presente trabajo se logró la maduración y conversión de embriones somáticos a plántulas completas en el medio de cultivo MS suplementado con ANA+BAP+AIA $\left(2 \mathrm{mg} \mathrm{L}^{-1}\right.$ de $\mathrm{c} / \mathrm{u}$ ), el cual contiene mayor número y tipo de auxinas que de citocininas, tanto en el medio de iniciación como en el de multiplicación, y a lo cual se atribuye que no haya habido inhibición del enraizamiento. George y Sherrington (1984) observaron que los elevados niveles endógenos de citocininas en algunas especies inhiben el enraizamiento, de modo que se requiere de varios subcultivos sin citocininas a fin de reducirlos y suprimir el bloqueo que ejerce su efecto.

La regeneración de plántulas a partir de ES depende tanto de la especie como de las condiciones de cultivo. Así, para Oncidium (Orchidaceae) la expansión secuencial de los embriones y su germinación en embriones cigóticos, ocurrió después de 2 a 3 semanas en el mismo medio de inducción (Chen y Chang, 2000). En el presente estudio, la inducción, maduración y desarrollo de plántulas de $L$. anceps ssp. dawsonii, ocurrió a las 8 semanas en el mismo medio de cultivo.

De acuerdo con estos resultados, se infiere que se logró establecer un protocolo completo de regeneración de plantas, y que la eficiencia de proliferación de embriones somáticos se promueve mediante subcultivos de los callos inicialmente regenerados, a intervalos de $45 \mathrm{~d}$ con fotoperiodo de $16 \mathrm{~h}\left(33.8 \mu \mathrm{mol} \mathrm{m}^{-2} \mathrm{~s}^{-1}\right)$, que permite la formación de 611 ES en el tercer subcultivo (S3), a los $135 \mathrm{~d}$ del cultivo in vitro. Los mayores promedios de formación de ES reportados para la familia Orchidaceae son de 59 (Chen y Chang, 2004 a), en Phalaenopsis amabilis var. Formosa Shimadzu, a partir de protocormos, en un proceso de embriogénesis repetitiva en fotoperiodo de $16 \mathrm{~h}\left(28-36 \mu \mathrm{mol} \mathrm{m}^{-2} \mathrm{~s}^{-1}\right)$, y de $134 \mathrm{ES}$ en las secciones adaxial, abaxial y terminal de explantes foliares de Oncidium (Chen y Chang, 2004 b).

\section{CONCLUSIONES}

Se estableció un protocolo rápido, simple y eficiente para la inducción de embriogénesis somática a partir de semillas de Laelia anceps ssp. dawsonii. Se encontró también que la competencia embriogénica depende de la interacción del explante con los factores del medio de cultivo (tipo de medio y composición de fitohormonas), número de subcultivos y condiciones de fotoperiodo. La combinación ANA + BAP+AIA $\left(2 \mathrm{mg} \mathrm{L}^{-1} \mathrm{de} \mathrm{c} / \mathrm{u}\right)$ resultó óptima para inducción de callo, con 611 embriones somáticos producidos bajo fotoperíodo de $16 \mathrm{~h}(33.8$

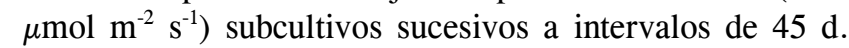
El medio VW suplementado con $2 \mathrm{mg} \mathrm{L}^{-1}$ de BAP +1.0 mg $\mathrm{L}^{-1}$ de AIA, resultó adecuado para el desarrollo de embriones somáticos a plántulas, que bajo condiciones de invernadero alcanzaron $95 \%$ de supervivencia. Este protocolo establecido por primera vez en esta especie puede contribuir al rescate, propagación y conservación de este valioso recurso ornamental, y ofrece la posibilidad de su cultivo sostenible para la producción comercial. 


\section{AGRADECIMIENTOS}

Los autores desean agradecer al Biólogo Antonio Bustos M., por proporcionar las plantas de Laelia anceps ssp. dawsonii utilizadas como fuente de explantes, a la Universidad Veracruzana por el soporte financiero, y al PROMEP-SEP como patrocinador de la beca para estudios doctorales.

\section{BIBLIOGRAFÍA}

Ávila I, R Salgado (2006) Propagación y mantenimiento in vitro de orquídeas mexicanas, para colaborar en su conservación. Rev. Biológicas, Fac. Biol. Univ. Michoacana Sn Nicolás de Hgo. 8:138-149.

Bechtel P G (1990) The Laelias of México. Amer. Orchid Soc. Bull. 59:1229-1234.

Chen J T, W C Chang (2004a) Induction of repetitive embryogenesis from seed-derived protocorms of Phalaenopsis amabilis var. Formosa Shimadzu. In vitro Cell. Develop. Biol. Plant 40:290293.

Chen J T, W C Chang (2004b) TIBA affects the induction of direct somatic embryogenesis from leaf explants of Oncidium. Plant Cell Tiss. Org. Cult. 79:315-320.

Chen J T, W C Chang (2003) Effects of $\mathrm{GA}_{3}$, ancymidol, cycocel and paclobutrazol on direct somatic embryogenesis of Oncidium in vitro. Plant Cell Tiss. Org. Cult. 72:105-108.

Chen J T, W C Chang (2000) Efficient plant regeneration through somatic embryogenesis from callus cultures of Oncidium (Orchidaceae). Plant Sci. 160:87-93.

Choi Y E, D C Yang, J C Park, WY Soh, K T Choi (1998) Regenerative ability of somatic single and multiple embryos from cotyledons of Korean ginseng on hormone-free medium. Plant Cell Rep. 17:544-551.

Dudits D, L Bögre, J. Györgyey (1991) Molecular and cellular approaches to the analysis of plant embryo development from somatic cells in vitro. J. Cell Sci. 99:475-484.

Fehér A, T P Pasternak, D Dudits (2003) Transition of somatic plant cells to an embryogenic state. Plant Cell Tiss. Org. Cult. 74:201-228

George E F, P D Sherrington (1984) Plant Propagation by Tissue Culture. Exegetics Ltd. Eversley, England. 1333 p.

Halbinger F (1993) Laelias de México. Asociación Mexicana de Orquideología, A.C. (Ed.) México, D.F. 71 p.

Huan L V, T Takamura, M Tanaka (2004) Callus formation and plant regeneration from callus through somatic embryo structures in Cymbidium orchid. Plant Sci. 166:1443-1449.

Knudson L (1946) A new nutrient solution for germination of orchid seed. Amer. Orchid Soc. Bull. 15:214-217.

Lee Y-I, N Lee (2003) Plant regeneration from protocorm-derived callus of Cypripedium formosanum. In vitro Cell. Develop. Biol. Plant 39:475-479.

Martin K P (2003) Clonal propagation, encapsulation and reintroduction of Ipsea malabarica (Reichb .f.) J.D. Hook., an endangered orchid. In vitro Cell. Develop. Biol. Plant 39:322326.

Martin K P, A K Pradeep (2003) Simple strategy for the in vitro conservation of Ipsea malabarica an endemic and endangered orchid of the Western Ghats of Kerala, India. Plant Cell Tiss. Org. Cult. 74:197-200.

Murashige T, F Skoog (1962) A revised medium for rapid growth and bioassays with tobacco tissue cultures. Physiol. Plant. 15:473497.
Murthy H N, A N Pyati (2001) Micropropagation of Aerides maculosum Lindl. (Orchidaceae). In vitro Cell. Develop. Biol. Plant 37:223-226.

Norma Oficial Mexicana NOM-059-ECOL (2002) Protección ambiental-especies nativas de México de flora y fauna silvestres: Categorías de riesgo y especificaciones para su inclusión, exclusión o cambio: Lista de especies en riesgo. Diario Oficial (6 de marzo 2002). México, D.F.

Piven N M, F A Barredo-Pool, I C Borges-Argáez, M A HerreraAlamillo, A Mayo-Mosqueda, J L Herrera, M L Robert (2001) Reproductive biology of henequén (Agave fourcroydes) and its wild ancestor Agave angustifolia (Agavaceae). I. Gametophyte development. Amer. J. Bot. 88:1966-1976.

Potisek M C, M Sarmiento, L N Puc (1996) Germinación de semillas y su establecimiento in vitro de Laelia rubescens Lindley y Epidendrum stamfordianum Batem. Reporte Anual de Ciencia y Tecnología INIFAP. CIR-SURESTE Campeche, Camp., México pp:187-192.

Rajasekaran K, M B Hein, G C Davis, M G Carnes, I K Vasil (1987) Exogenous growth regulators in leaves and tissue cultures of Pennisetum purpureum Schum. J. Plant Physiol. 130:13-25

Rao A T (1998) Conservation of Wild Orchids of Kodagu in the Western Ghats. Bangalore: The Technology Development and Agricultural Technologies and Services Pvt. Ltd. 242 p.

Sagare A P, Y L Lee, T C Lin, C C Chen, H S Tsay (2000) Cytokinin-induced somatic embryogenesis and plant regeneration in Corydalis yanhusuo (Fumariaceae) - a medicinal plant. Plant Sci. 160:139-147.

Santos-Hernández L, M Martínez-García, J E Campos, E AguirreLeón (2005) In vitro propagation of Laelia albida (Orchidaceae) for Conservation and Ornamental Purposes in México. HortScience 40:439-442.

SAS (1989-1997) Version 6.12, SAS Institute Inc., Cary, NC, USA

Seeni S, P G Latha (1992) Foliar regeneration of the endangered Red Vanda, Renanthera imschootiana Rolfe (Orchidaceae). Plant Cell Tiss. Org. Cult. 29:167-72.

Shimura H, Y Koda (2004) Micropropagation of Cypropedium macranthos var. rebunense through protocorms-like bodies derived from mature seeds. Plant Cell Tiss. Org. Cult. 78:273276.

Soto A M A (1993) Clasificación intraespecífica de Laelia anceps. Orquídea (Méx.) 11:233-277.

Steel R G, J H Torrie (1980) Principles and Procedures of Statistics a Biometrical Approach. 2 ed. Mc Graw Hill. New York. 633 p.

Vacin E F, F W Went (1949) Some pH changes in nutrient solutions. Bot. Gazette 110: 605-613. 